\title{
Evolution of development in nematodes related to C. elegans ${ }^{\star}$
}

\author{
Ralf J. Sommer ${ }^{\S}$, Max-Planck Institut für Entwicklungsbiologie, \\ Abteilung Evolutionsbiologie, D-72076 Tübingen, Germany
}

\section{Table of Contents}

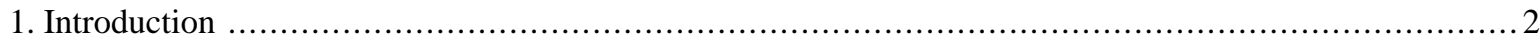

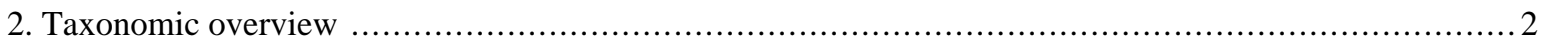

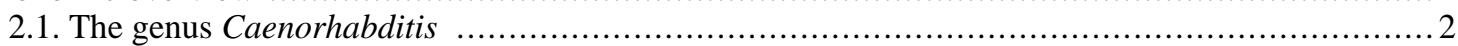

2.2. The family Rhabditidae ....................................................................... 2

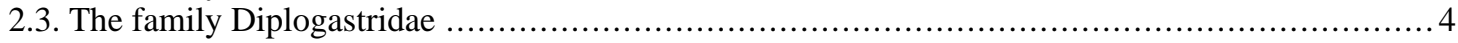

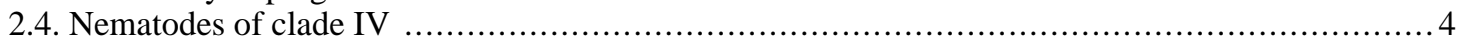

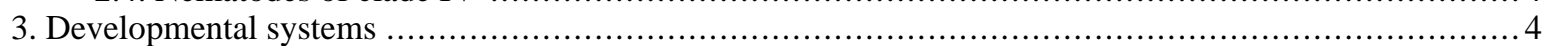

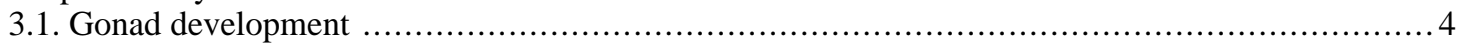

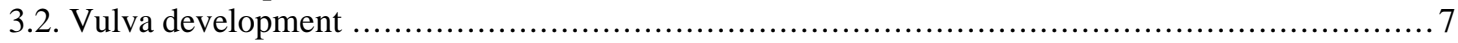

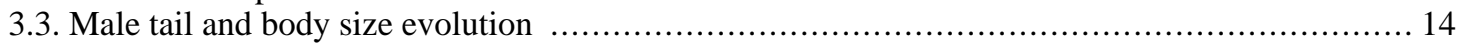

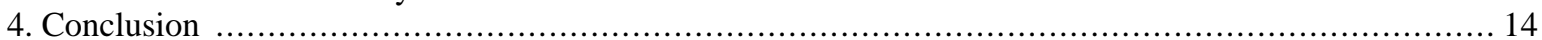

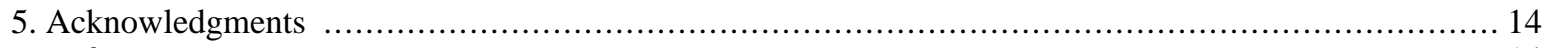

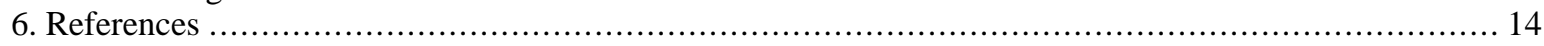

\begin{abstract}
The knowledge about $C$. elegans provides a paradigm for comparative studies. Nematodes are very attractive in evolutionary developmental biology given the species richness of the phylum and the easiness with which several of these species can be cultured under laboratory conditions. Embryonic, gonad, vulva and male tail development were studied and compared in nematodes of five different families, providing a detailed picture of evolutionary changes in development. In particular, vulva development has been studied in great detail and substantial differences in the cellular, genetic and molecular mechanisms have been observed between $C$. elegans and other nematodes. For example, vulva induction relies on the single anchor cell in $C$. elegans, whereas a variety of different cellular mechanisms are used in related species. In recent years, a few species have been developed as satellite systems for detailed genetic and molecular studies, such as Oscheius tipulae and Pristionchus pacificus.
\end{abstract}

\footnotetext{
"Edited by David H. A. Fitch. Last revised March 28, 2005. Published December 14, 2005. This chapter should be cited as: Sommer, R.J. Evolution of development in nematodes related to C. elegans (December 14, 2005), WormBook, ed. The C. elegans Research Community, WormBook, doi/10.1895/wormbook.1.46.1, http://www.wormbook.org.

Copyright: (C) 2005 Ralf J. Sommer. This is an open-access article distributed under the terms of the Creative Commons Attribution License, which permits unrestricted use, distribution, and reproduction in any medium, provided the original author and source are credited

${ }^{\S}$ To whom correspondence should be addressed. E-mail: ralf.sommer@tuebingen.mpg.de
} 


\section{Introduction}

The comparison of just a handful of animal model organisms has provided powerful insight into the mechanisms of life. C. elegans is one such model organism that has contributed greatly to the understanding of modern biology. With the knowledge about "The Worm" in hand, one can now use C. elegans as a paradigm in comparative biology. How do developmental processes vary among nematode species? How have these processes evolved? How representative are certain aspects of $C$. elegans development for other nematodes? What are the directions of evolutionary change? And ultimately, can we learn something about $C$. elegans itself by comparing it with its peers and by placing it into a broader context? Evolutionary developmental biology tries to tackle these problems.

Nematodes are very attractive in evolutionary developmental biology. The nematode phylum is very rich in species and many of them can be cultured under laboratory conditions. Similar to C. elegans, most other nematodes that have been investigated display an invariant cell lineage and thus, developmental processes can be studied with cellular resolution. The combination of cell lineage analysis with cell ablation by laser microbeam irradiation provides a meaningful entry point for comparative studies and can be carried out in multiple species. Such "multiple species comparisons" provide a comprehensive overview about developmental variations in a phylogenetic context. For certain aspects of development, such as embryonic, gonad, vulva and male tail development, representatives of up to five nematode families have been compared in the last decade, providing a detailed picture of evolutionary changes in development that is unique in the animal kingdom.

The following chapter is divided in two parts. The first part provides a brief overview of the investigated species. More detailed phylogenetic information about nematodes can be obtained in another chapter (see A quick tour of nematode diversity and the backbone of nematode phylogeny). The second part introduces the evolution of some developmental processes in more detail. These are vulva and gonad development in hermaphrodites/females, male tail development and body size. Embryonic development and sex determination are covered separately, see Embryological variation during nematode development and The evolution of nematode sex determination, respectively.

\section{Taxonomic overview}

\subsection{The genus Caenorhabditis}

Most functional studies of $C$. elegans have been performed with the laboratory strain N2. It is important to realize that $\mathrm{N} 2$ is just one isolate of $C$. elegans and that $C$. elegans itself is just one of many species in the ecologically very diverse genus Caenorhabditis (see Ecology of Caenorhabditis species). In recent years, C. elegans population genetics and genomic analysis of the closely related species $C$. briggsae and $C$. remanei have received detailed attention and are covered in separate chapters (see Nematode genome evolution and Natural variation and population genetics of C. elegans).

One novel focus of comparative studies within $C$. elegans is on microevolution. Such comparisons can identify polymorphisms of characters within one species. For example, vulva cell lineage comparison between $C$. elegans strains revealed polymorphisms that could explain the evolutionary variations seen between closely related species (Delattre and Felix, 2001a). Also, recent studies have identified differences between $C$. elegans and $C$. briggsae in the final morphology of the excretory duct. Interestingly, expression of the lin-48 ovo gene in C. elegans plays a crucial role in the evolutionary diversification of duct morphology (Wang and Chamberlin, 2002).

\subsection{The family Rhabditidae}

The genus Caenorhabditis belongs to the family Rhabditidae (called "rhabitids" in The phylogenetic relationships of Caenorhabditis and other rhabditids). This family consists of more than two hundred described free-living species and is subdivided into approximately 10 different genera (see The phylogenetic relationships of Caenorhabditis and other rhabditids). Within this group interesting morphological differences are seen (Table 1): some species have females with a one-armed (monodelphic) gonad rather than the two-armed (didelphic) gonad known from $C$. elegans. Or, the vulva forms posteriorly, as in Mesorhabditis. The life history traits vary substantially, with most species being gonochoristic (male-female species). In some genera (Mesorhabditis), pseudogamy and parthenogenesis are dominating and hermaphroditic species are basically restricted to two genera, Caenorhabditis and Oscheius (Table 1). 
Given the gonochoristic and parthenogenetic life style, representatives of the genera Mesorhabditis, Teratorhabditis, Cruznema, Pelodera, Rhabditoides, to name just a few, have often just been investigated in initial cell lineage comparisons (Table 1). Usually, these broad comparisons served in the identification of promising species for more detailed genetic and molecular studies (satellite organisms).

Table 1. Summary of gonad and vulva character in representative clade IV and clade V species

\begin{tabular}{|c|c|c|c|c|c|c|c|c|}
\hline Genus & Species & LH & $\mathrm{C} / \mathrm{F}$ & Gonad & \begin{tabular}{|l|} 
Vulva: \\
Pos./PCD
\end{tabular} & Induction & Pattern & Reference \\
\hline Caenorhabditis & C. elegans & $\mathrm{H}$ & V: R & Di & Central/- & 1-step & $2^{\circ}-1^{\circ}-2^{\circ}$ & \\
\hline Oscheius & O. tipulae & $\mathrm{H}$ & $\mathrm{V}: \mathrm{R}$ & $\mathrm{Di}$ & Central/- & 2-step & $2^{\circ}-1^{\circ}-2^{\circ}$ & $\begin{array}{l}\text { see sections } \\
3.1 .2 / 3.2 .3 \text {. }\end{array}$ \\
\hline Rhabditella & R. axei & G & $\mathrm{V}: \mathrm{R}$ & Di & Central/- & 2-step & $2^{\circ}-1^{\circ}-2^{\circ}$ & \begin{tabular}{|l|} 
Felix and \\
Sternberg, 1997
\end{tabular} \\
\hline Rhabditoides & R. regina & G & V: R & Di & Central/- & $\begin{array}{l}\text { Gonad } \\
\text { dep.* }\end{array}$ & $2^{\circ}-1^{\circ}-2^{\circ}$ & $\begin{array}{l}\text { Sommer and } \\
\text { Sternberg, } 1995\end{array}$ \\
\hline Pelodera & P. strongyloides & G & V: R & Di & Central/- & n.d. & $2^{\circ}-1^{\circ}-2^{\circ}$ & $\begin{array}{l}\text { Sommer and } \\
\text { Sternberg, } 1995\end{array}$ \\
\hline Mesorhabditis & M. sp. PS1179 & Ps & V: R & Mono & Posterior/- & $\begin{array}{l}\text { no gonad } \\
\text { ind. }\end{array}$ & $2^{\circ}-1^{\circ}-2^{\circ}$ & $\begin{array}{l}\text { Felix and } \\
\text { Sternberg, } 1996\end{array}$ \\
\hline Teratorhabditis & T. palmarum & G & V:R & Mono & Posterior/- & $\begin{array}{l}\text { no gonad } \\
\text { ind. }\end{array}$ & $2^{\circ}-1^{\circ}-2^{\circ}$ & $\begin{array}{l}\text { Sommer and } \\
\text { Sternberg, } 1994\end{array}$ \\
\hline Cruznema & C. tripartitum & G & V:R & Mono & Posterior/- & $\begin{array}{l}\text { Gonad } \\
\text { dep.* }\end{array}$ & $2^{\circ}-1^{\circ}-2^{\circ}$ & $\begin{array}{l}\text { Sommer and } \\
\text { Sternberg, } 1994\end{array}$ \\
\hline Poikilolaimus & P. oxycerca & G & V: R & Di & Central/+ & n.d. & $2^{\circ}-1^{\circ}-2^{\circ}$ & \begin{tabular}{|l|} 
Sommer and \\
Sternberg, 1996
\end{tabular} \\
\hline Pristionchus & P.pacificus & $\mathrm{H}$ & V: D & Di & Central/+ & continuous & $2^{\circ}-1^{\circ}-2^{\circ}$ & $\begin{array}{l}\text { see sections } \\
\text { 3.1.3./3.2.4. }\end{array}$ \\
\hline Koerneria & K. sp. RS 113 & G & V: D & Di & Central/+ & $\begin{array}{l}\text { Gonad } \\
\text { dep.* }\end{array}$ & $2^{\circ}-1^{\circ}-2^{\circ}$ & \begin{tabular}{|l|} 
Sternberg and \\
Horvitz, 1981
\end{tabular} \\
\hline Diplogasteroides & D. sp. RS125 & $\mathrm{H}$ & V: D & Di & Central/+ & $\begin{array}{l}\text { Gonad } \\
\text { dep.* }\end{array}$ & $2^{\circ}-1^{\circ}-2^{\circ}$ & \begin{tabular}{|l|} 
Sternberg and \\
Horvitz, 1981
\end{tabular} \\
\hline Aduncospiculum & A. halicti & G & V: D & Di & Central/+ & $\begin{array}{l}\text { Gonad } \\
\text { dep.* }\end{array}$ & $2^{\circ}-1^{\circ}-2^{\circ}$ & \begin{tabular}{|l|} 
Sternberg and \\
Horvitz, 1981
\end{tabular} \\
\hline Goodeyus & G. ulmi & G & V: D & Di & Central/+ & $\begin{array}{l}\text { Gonad } \\
\text { dep.* }\end{array}$ & $2^{\circ}-1^{\circ}-2^{\circ}$ & \begin{tabular}{|l} 
Sternberg and \\
Horvitz, 1981
\end{tabular} \\
\hline Diplogastrellus & D. gracilis & G & V: D & Di & Posterior/+ & $\begin{array}{l}\text { no gonad } \\
\text { ind. }\end{array}$ & $2^{\circ}-1^{\circ}-2^{\circ}$ & unpublished \\
\hline Panagrolaimus & P. sp. PS 1732 & $\mathrm{H}$ & IV: P & Mono & Central /+ & 2-step & $2^{\circ}-1^{\circ}-1^{\circ}-2^{\circ}$ & Felix et al., 2000 \\
\hline Panagrellus & P. redivivus & G & IV: P & Mono & Posterior/- & 2-step & $2^{\circ}-1^{\circ}-1^{\circ}-2^{\circ}$ & \begin{tabular}{|l} 
Sternberg and \\
Horvitz, 1981/ \\
Felix et al., 2000
\end{tabular} \\
\hline Turbatrix & T. aceti & G & IV: P & Mono & Posterior/+ & 2-step & $2^{\circ}-1^{\circ}-1^{\circ}-2^{\circ}$ & Felix et al., 2000 \\
\hline Halicephalobus & H. sp. JB128 & $\mathrm{P}$ & IV: P & Mono & Central /+ & 3-step & $2^{\circ}-1^{\circ}-1^{\circ}-2^{\circ}$ & Felix et al., 2000 \\
\hline Brevibucca & B. sp. SB 261 & G & IV: B & Mono & Posterior/- & $\begin{array}{l}\text { no gonad } \\
\text { ind. }\end{array}$ & $2^{\circ}-1^{\circ}-1^{\circ}-2^{\circ}$ & Felix et al., 2000 \\
\hline Cephalobus & C. cubaensis & $\mathrm{P}$ & IV: C & Mono & Central/+ & 1-step \# & $2^{\circ}-1^{\circ}-1^{\circ}-2^{\circ}$ & Felix et al., 2000 \\
\hline
\end{tabular}




\begin{tabular}{|c|c|c|c|c|c|c|c|c|}
\hline Genus & Species & LH & $\mathbf{C} / \mathrm{F}$ & Gonad & $\begin{array}{l}\text { Vulva: } \\
\text { Pos./PCD }\end{array}$ & Induction & Pattern & Reference \\
\hline Myolaimus & M. heterurns & G & IV: M & Mono & Central/- & n.d. & $2^{\circ}-1^{\circ}-1^{\circ}-2^{\circ}$ & Felix et al., 2000 \\
\hline Strongyloides & S. ratti§ & G/P & IV: $\mathrm{S}$ & Di & Central/- & n.d. & $1^{\circ}-1^{\circ}$ & Felix et al., 2000 \\
\hline \multicolumn{9}{|l|}{ Abbreviations: } \\
\hline \multicolumn{9}{|c|}{ LH=Life history; H, hermaphroditic; G, gonochoristic (male/female); P, parthenogenetic; Ps, pseudogamy } \\
\hline \multicolumn{9}{|c|}{$\begin{array}{l}\mathrm{C} / \mathrm{F}=\text { Clade/Family: clade V, IV according to molecular phylogeny, see chapter XII-A. R, Rhabditidae; D, } \\
\text { Diplogastridae; P, Panagrolaimidae; B, Brevibuccidae; C, Cephalobidae; M, Myolaimidae; S, Strongyloididae }\end{array}$} \\
\hline \multicolumn{9}{|c|}{ Gonad: didelphic (Di), Monodelphic (Mono) } \\
\hline \multicolumn{9}{|c|}{$\begin{array}{l}\text { Vulva: Pos./PCD: Vulva position (Pos); PCD: programmed cell death of anterior and/or posterior non-vulval } \\
\text { epidermal cells (+), no PCD (-) }\end{array}$} \\
\hline \multicolumn{9}{|c|}{$\begin{array}{l}\text { Gonad dep.*: Ablation of } \mathrm{Z}(1,4) \text {, the precursors of the somatic gonad results in the absence of a vulva. No detailed } \\
\text { cell lineage experiments performed. }\end{array}$} \\
\hline \multicolumn{9}{|c|}{ \# In C. cubaensis, the first specification step of vulval vs. non-vulva is gonad independent (Felix et al., 2000) } \\
\hline \multicolumn{9}{|c|}{$\begin{array}{l}\S \text { In } S \text {. ratti, only the free-living females have been analyzed. The vulva is formed by P6.p and P7.p only and the } \\
\text { progeny of both cells contribute to the outer and inner fates. }\end{array}$} \\
\hline
\end{tabular}

\subsection{The family Diplogastridae}

The Diplogastridae (called "diplogastrids" in The phylogenetic relationships of Caenorhabditis and other rhabditids) include about 300 described free-living species in 28 genera (Fürst v. Lieven and Sudhaus, 2000, 2003). Although the exact phylogenetic relationship to the Rhabditidae is still debated (sister group relationship vs. Diplogastridae nested within the Rhabditidae), it is evident that the two families are most closely related (see The phylogenetic relationships of Caenorhabditis and other rhabditids). Most species are gonochoristic and hermaphrodites have only been described in two genera, Diplogasteroides and Pristionchus. P. pacificus has been established as a satellite organism in evolutionary developmental biology in the last ten years (see section 3.2.4. below).

\subsection{Nematodes of clade IV}

The Rhabditidae and Diplogastridae both belong to clade $\mathrm{V}$ nematodes according to the molecular phylogeny of nematodes (Blaxter et al., 1998; see A quick tour of nematode diversity and the backbone of nematode phylogeny). The closest relatives of clade $\mathrm{V}$ are members of clade IV, including the Panagrolaimidae and Cephalobidae. Most species of clade IV are gonochoristic or parthenogenetic (Table 1) and have long generation times. Various developmental processes have been compared by cell lineage and cell ablation studies, but no single species has been established as a particular satellite system for genetic and molecular studies (Table 1). One species of this clade is Panagrellus redivivus, which was the first species to be compared with $C$. elegans at the cell lineage level. Sternberg and Horvitz described the complete postembryonic cell lineage of P. redivivus (Sternberg and Horvitz, 1981, Sternberg and Horvitz, 1982).

\section{Developmental systems}

Given space restrictions, I will focus my description on gonad development, vulva formation, male tail development and body size. I apologize to those colleagues whose work I am unable to review.

\subsection{Gonad development}

The $C$. elegans hermaphrodite gonad has been shown to be a powerful system for studying fundamental problems in developmental and cell biology (see Developmental control mechanisms and Cell biology sections of WormBook). Asymmetric cell divisions, cell-cell signaling and cell migration are all equally important during gonad development and genetic and molecular studies provided detailed insight into the underlying mechanisms. At the same time nematode gonads vary substantially between the two sexes and across species. In males, gonads are 
always monodelphic, that is one-armed. In most nematodes female/hermaphrodite gonads are didelphic (two-armed), but monodelphic species are known from all families studied so far in evolutionary developmental biology (Table 1). It is still debated whether monodelphy or didelphy represents the ancestral character state. In any case, convergent evolution of gonad morphology is likely, considering the many cases in which didelphic and monodelphic species coexist in the same nematode family.

\subsubsection{Nematodes with monodelphic female gonads}

In C. elegans hermaphrodites, the two gonad arms develop nearly symmetrically from two somatic precursor cells, Z1 (anterior arm) and Z4 (posterior arm). Each of these cells gives rise to a distal tip cell (DTC; Z1.aa and Z4.pp), which promotes the growth and migration of the arm and later, the proliferation of the germ line (see Introduction to the germ line).

The first species with a monodelphic female gonad that was studied in greater detail was Panagrellus redivivus (Sternberg and Horvitz, 1981). Cell lineage analysis revealed that monodelphy results from the programmed cell death of the posterior dtc Z4.pp (Figure 1). Thus, the programmed cell death of a single cell has a major influence on overall nematode morphology.

Within the Rhabditidae, didelphy is thought to represent the ancestral character state. Monodelphy has evolved repeatedly, such as in the genera Mesorhabditis, Teratorhabditis and Cruznema. Felix and Sternberg analyzed representatives of these genera and additional species within the genera Cephalobus, Acrobeloides and Panagrolaimus (Felix and Sternberg, 1996). In all these cases, the first asymmetry between the anterior and posterior part of the gonad was already seen at the time of Z1 and Z4 division. The lineage that produces Z4.pp dies in all these species, albeit, at different time points in development (Felix and Sternberg, 1996; Figure 1).

Finally, it should be noted that the evolutionary diversification resulting in female monodelphy is distinct from one-armed gonads in males. C. elegans male gonad development does not involve programmed cell death and the posterior elongation requires a novel cell type, the linker cell (see Introduction to the germ line; Figure 1).

\subsubsection{Anchor cell specification and function in monodelphic species}

Later in development, the female/hermaphrodite gonad generates a unique cell type, the anchor cell (AC). The AC is morphologically distinct from all other cells of the somatic gonad (Sherwood and Sternberg, 2003). This cell is important for signaling to other ventral uterine cells, is involved in vulva induction and finally generates the connection between the uterus and the outside environment (Newman and Sternberg, 1996). The AC is determined by stochastic events, in that Z1.ppp and Z4.aaa have an equal chance of adopting the AC fate. lin-12 signaling is instrumental in AC specification (see LIN-12/Notch signaling in C. elegans). Recent studies suggest that the birth order of Z1.ppp and Z4.aaa is crucial for AC specification (Karp and Greenwald, 2003). Females/hermaphrodites of all nematode species studied to date generate an AC. Interestingly, AC specification is highly biased or even fixed in most monodelphic species (Felix and Sternberg, 1996).

As will be discussed below, monodelphic species always form a posterior vulva, rather than a vulva that is localized in the center of the animal. However, the degree to which the vulva is shifted to the posterior is species-specific and varies between $60-90 \%$ body length. In this context, it is noteworthy that vulva induction can be performed by cells other than the AC. In Mesorhabdits sp. PS1179, the AC is no longer involved in vulva induction (Sommer and Sternberg, 1994). However, Z1.apr becomes the AC in Mesorhabditis and assumes a new function: it leads the elongation of the gonad towards the posterior vulva (Felix and Sternberg, 1996) demonstrating the evolutionary plasticity of individual cells. 

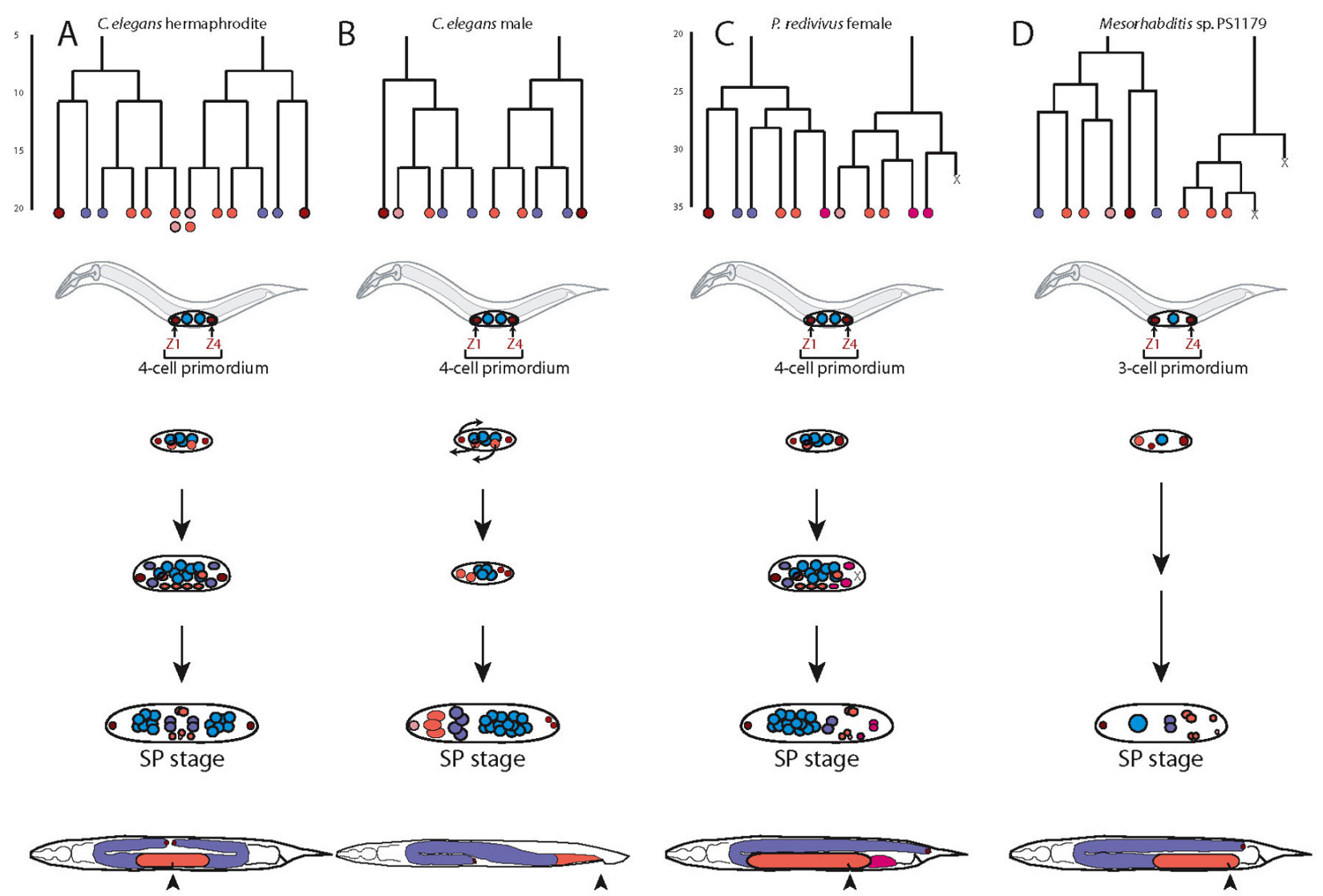

Figure 1. Didelphic and monodelphic nematode gonads. Cell linage and gonad development in: C. elegans hemaphrodites (A), C. elegans males (B), Panagrellus redivivus females (C), and Mesorhabditis sp. 1179 females (D). Lineages: Line length represents the relative timing of divisions. Terminal Xs at the lineage base represent cell deaths; terminal colors represent the predominant fate of the progeny of those cells: Dark red DTCs (distal tip cells): Purple, sheath/spermatheca in females and seminal vesicle in males; Red, uterus in females and vas deferens in males; Light pink, anchor cell in females and the linker cell in males; Dark pink, posterior pouch in P. redivivus females. Diagrams of gonad development: Diagrams of the initial somatic divisions and the somatic gonad primordium (SP) stage are shown for all animals; intermediate stages shown vary between animals. Small colored circles represent the relative position of nuclei. Colors in the lineages correlate to the colors of individual nuclei at the SP stage. Arrows represent migrations in the $C$. elegans male gonad to break the symmetry of the gonad. Mesorhabditis starts with a 3-cell primordium as a single germline precursor is present. Arrowheads represent the position of the vulva and the cloaca. Reprinted from Rudel and Sommer (2003), with permission.

\subsubsection{Didelphic species}

Hermaphrodite gonad development has also been compared between didelphic species. In particular, the Pristionchus pacificus hermaphrodite gonad has been studied in some detail by electron and fluorescent microscopy (Rudel et al., 2005; see section 3.2.4. for more detailed species overview). Although also didelphic, the P. pacificus gonad shows numerous differences in comparison to $C$. elegans (Figure 2). Among these differences are heterochronic changes, novel gonad arm-migrations, novel cellular composition of some tissues, the absence of a tissue (i.e. the spermathecal valve cells), a novel architecture for the sheath, and changes in the cellular and sub-cellular morphology of the individual sheath cells. Additionally, cell ablation experiments in P. pacificus indicate extensive cell communication between the somatic gonadal tissues and the germ line and some of which show significant differences in comparison to C. elegans (Rudel et al., 2005). 
The $P$. pacificus hermaphrodite gonad

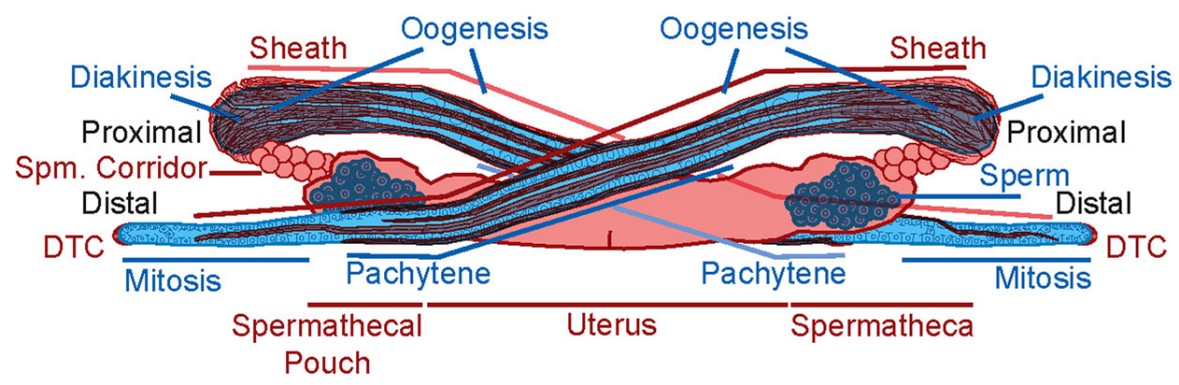

The C. elegans hermaphrodite gonad

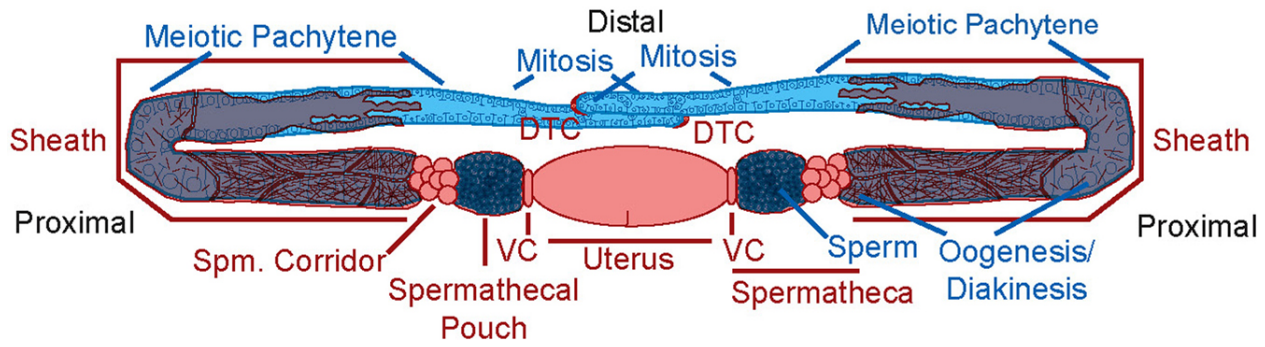

Figure 2. A cartoon comparison of the P. pacificus and C. elegans adult hermaphrodite gonads. Somatic tissues are shown in red, germline tissues in blue. Differences shown include: (1) The path of gonadal arm migration. (2) The morphology of the turn of the gonadal arms. (3) The cellular composition of the sheath and spermathecal corridor. (4) The cellular and sub-cellular morphology of the sheath (thin red lines represent actin filaments). (5) The absence of valve cells (VC) in P. pacificus. (6) The extent of diakinesis in the germ line. (7) A difference in size between sperm. Reprinted from Rudel et al., (2005), with permission.

Taken together, the nematode gonad shows enormously evolutionary diversity, both, at the level of the overall morphology and cell type specificity. Future work will allow the dissection of the molecular mechanisms involved in this evolutionary diversification by studying selected examples in more detail.

\subsection{Vulva development}

C. elegans vulva formation is one of the best studied processes in animal development (see Vulval development). Initial genetic and molecular analyses revealed the involvement of EGF/RAS/MAPK signaling in vulva formation and these similarities to oncogenesis initiated a boost in studies on vulva development.

Vulva development occurs in the late L3 and L4 stage. All cell divisions takes place within five hours and vulva formation represents, to a large extent, a two-dimensional process that is easy to follow by Nomarski microscopy. In short, three of twelve ventral epidermal cells divide in three consecutive rounds to generate a total of 22 progeny that form the vulva (Sulston and Horvitz, 1977). The three vulva precursor cells (VPC) P(5-7).p adopt one of two alternative cell fates. $\mathrm{P}(5,7)$.p have a $2^{\circ}$ fate and form the anterior and posterior part of the vulva, whereas P6.p has the $1^{\circ}$ fate and forms the inner part of the vulva (Figures $3 \mathrm{~A}$ and $6 \mathrm{~A}$ ). 
A

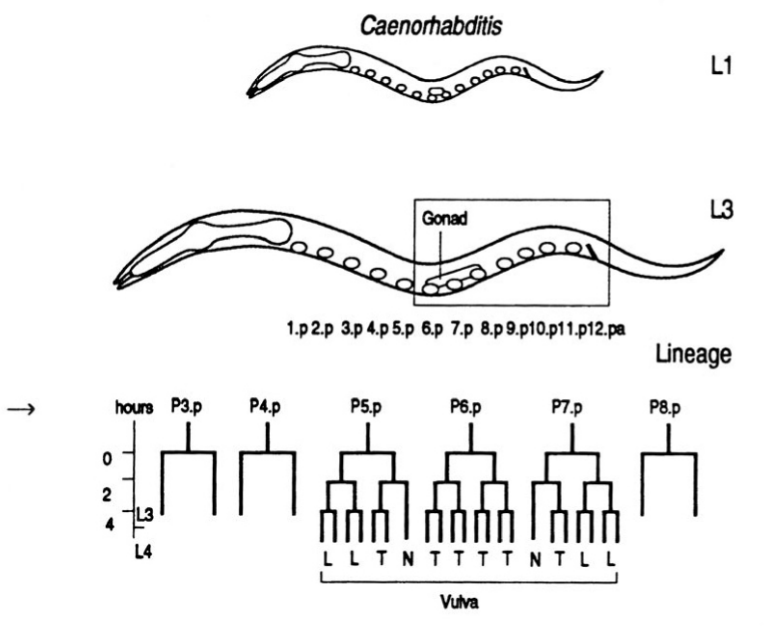

B

Cruznema

L3

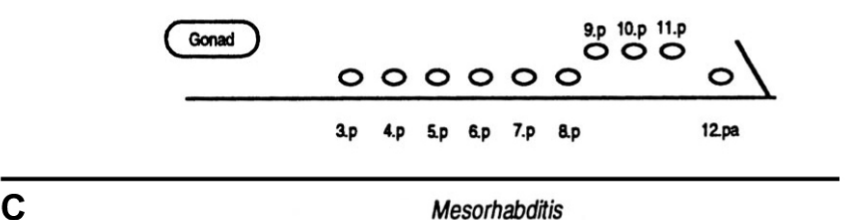

L3
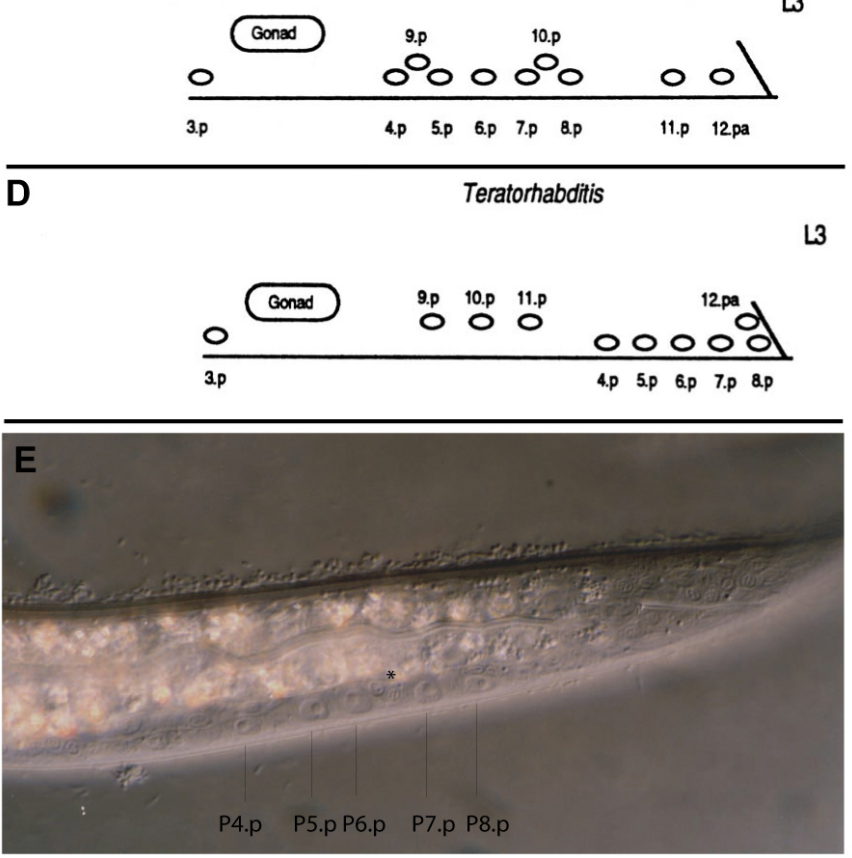

Figure 3. Schematic summary of the different positions of the Pn.p ectoblasts in the L1 stage and the early L3 stage as a result of cell migrations in $C$. elegans (A), Cruznema tripartitum (B), Mesorhabditis sp. PS1179 (C, E), Teratorhabditis palmarum (D). In the L1 stage (A), the 12 Pn.p cells are equally distributed in the region between the pharynx and the rectum. This stage is shown for $C$. elegans only, but also holds for other species. The final vulval pattern of C. elegans is shown in Fig. 6A. P(3-8).p in C. tripartitum and P(4-8).p in M. sp. PS1179 and T. palmarum migrate to the posterior region in the L2 stage. In the early L3 stage, these cells have species-specific positions relative to the posterior Pn.p cells (B-E). (B), (C) and (D) show a higher magnification of the corresponding body region indicated by the box in (A). (E) Nomarski photomicrograph of a M. sp. PS1179 animal in the early L3 stage. P(4-8).p reached their final posterior position and have pushed some other Pn.p cells, such as P9.p and P10.p (asterisk) out of their way. The vulva cell lineage is only shown for $C$. elegans, $\mathrm{T}$ (transverse), L (longitudinal) and $\mathrm{N}$ (no division) refer to the division axis of the third division of the Pn.pxx cells (see Vulval development). The arrow in (A) marks the time point of vulva induction. 
The special interest of developmental biologists into vulva development results from two observations that were made following the ablation of different cells. First, although the vulva cell lineage is invariant in wild-type animals, if $\mathrm{P}(5-7)$.p are killed by laser microbeam irradiation they can be replaced by their three neighbors $\mathrm{P}(3,4,8)$.p (Sulston and White, 1980). Thus, there is a group of six cells, P(3-8).p that form a so-called vulva equivalence group and these cells adopt the anteroposterior pattern $3^{\circ}-3^{\circ}-2^{\circ}-1^{\circ}-2^{\circ}-3^{\circ}$. P3.p, P4.p and P8.p have an epidermal fate in non-ablated animals, which has been designated as $3^{\circ}$ fate. The second important observation was that vulva formation is initiated by a signal from the gonadal AC (Kimble, 1981; Figures 3A and 6A; see LIN-12/Notch signaling in C. elegans).

Detailed genetic and molecular studies revealed that at least four different signaling processes interact during vulva formation (see Vulval development). These are EGF signaling (see RTKRas/MAP kinase signaling), Wnt signaling (see Wnt signaling) and DSL/LIN-12 signaling (see LIN-12/Notch signaling in C. elegans), all of which act in a redundant manner during vulva induction. In addition, the NURD complex is involved in a negative signaling system that counteracts vulva induction (Lu and Horvitz, 1998; Ceol and Horvitz, 2004; Myers and Greenwald, 2005). Over the years, the detailed analysis of vulva development became a paradigm for signaling processes in animal development and thus, provides a platform for studying evolutionary developmental biology.

\subsubsection{Monodelphic species and posterior vulva development}

Vulva development was initially chosen for comparative studies because of the detailed genetic and molecular understanding of the process in C. elegans and the ease with which the vulva cell lineage could be determined and manipulated in novel species. First investigations concentrated on different rhabditid nematodes (Ambros and Fixsen, 1987; Sommer and Sternberg, 1994; Sommer and Sternberg, 1995; Sommer and Sternberg, 1996) with a specific emphasis on nematodes with posterior vulva formation (Sommer and Sternberg, 1994). Most nematodes that develop a monodelphic gonad form their vulva in the posterior body region (Figure 3; Table 1). In some species, such as Mesorhabditis sp. PS1179, vulva formation occurs at $80 \%$ body length, whereas in others, such as Teratorhabdits palmarum, it occurs at $90 \%$ body length in immediate proximity to the rectum (Figure 3 ). Surprisingly, in all studied cases the vulva developed from $\mathrm{P}(5-7)$.p with a $2^{\circ}-1^{\circ}-2^{\circ}$ pattern very similar to $C$. elegans. $\mathrm{P}(5-7) . \mathrm{p}$ are born in the central body region and migrate in the L2 stage, together with the other cells of the vulva equivalence group, towards the posterior. Migration stops at a species-specific position and cell divisions occur at the late L3 and early L4 stage (Figure 3).

Besides the involvement of cell migration, most species with posterior vulva formation differ from C. elegans in that the gonad no longer provides an inductive signal (Figure 4, Table 1; Sommer and Sternberg, 1994). If the gonad is ablated at hatching, a normal vulva forms in the absence of any gonadal tissue. This pattern has been observed in Mesorhabditis sp. PS1179 and T. palmarum (Sommer and Sternberg, 1994) of the Rhabditidae, in Brevibucca sp., SB261 of the Brevibuccidae (Felix et al., 2000) and in Diplogastrellus gracilis of the Diplogastridae (Sommer, unpublished observation; Table 1). Thus, posterior vulva formation in monodelphic species has evolved several times independently by convergent evolution and always requires cell migration of VPCs that were born in the central body region. In most cases - and again this feature has evolved independently by convergent evolution posterior vulva species do not require an inductive signal by the gonad. One exception is Cruznema tripartitum, in which $\mathrm{P}(3-8)$.p migrate towards the posterior in the L2 stage, as in the other species, but vulva formation requires induction by the AC. 


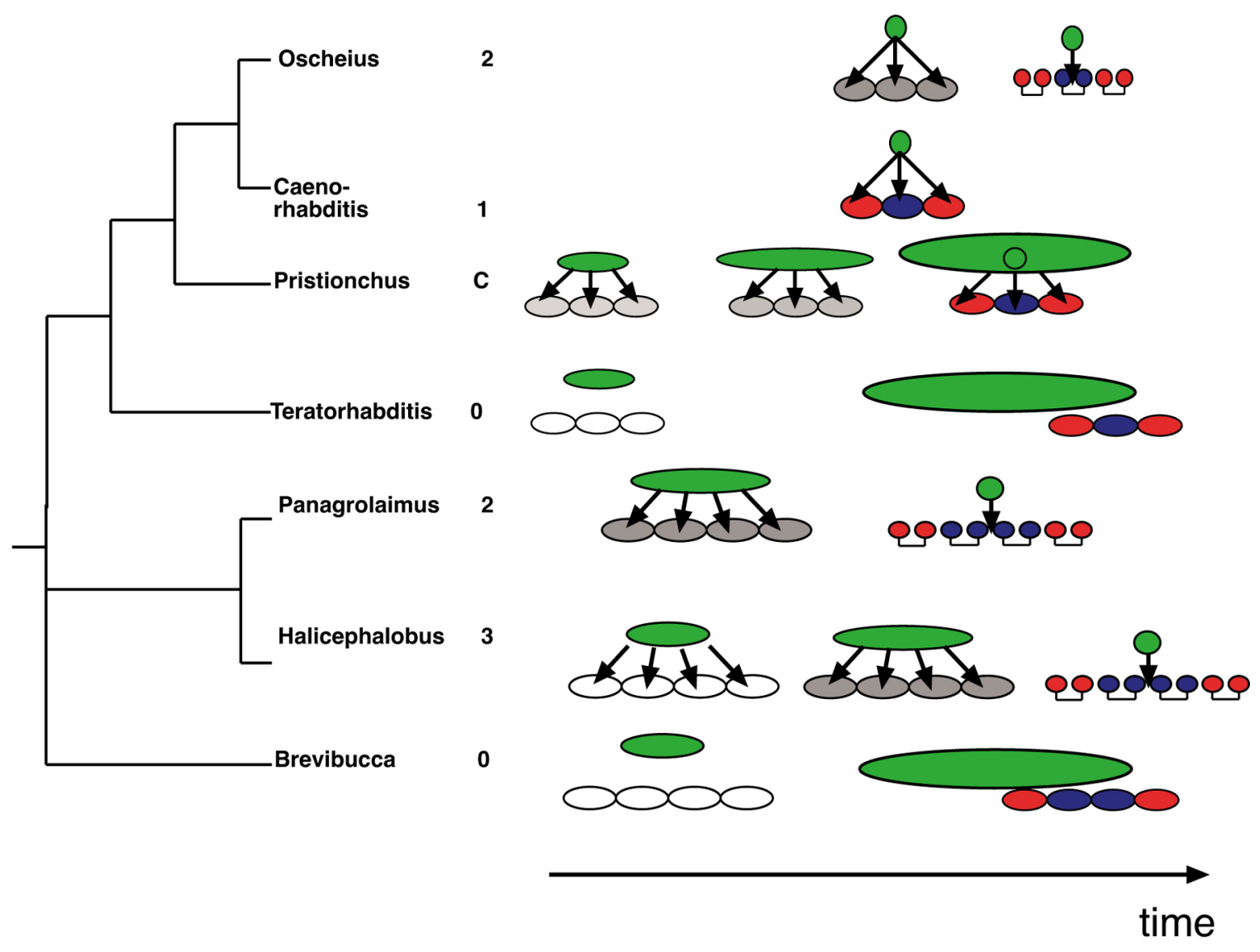

Figure 4. Modes of vulva induction in selected clade IV and clade V species. Oscheius, 2-step induction with both steps provided by the AC. C. elegans, 1-step induction. Pristionchus pacificus, continuous (C) induction from early gonadal stages to the birth of the AC. Teratorhabditis palmarum and Brevibucca sp. SB261 are species with a posterior vulva that do not require induction by the gonad. Panagrolaimus sp. PS1732 and Halocephalobus sp. JB128 have a 2-step and 3-step induction, respectively. Arrows indicate cell-cell interactions. The gonad and the AC are shown in green. Outer $\left(2^{\circ}\right)$ vulval fates are shown in red, the inner $\left(1^{\circ}\right)$ vulval fates are shown in blue. Intermediate specified vulval fates are shown in grey. Note that the Cephalobina pattern $2^{\circ}-1^{\circ}-1^{\circ}-2^{\circ}$ is a simplification (see section 3.2.2 for details). Reprinted from Sommer (2000), Copyright (2000) with permission from Elsevier.

\subsubsection{Vulval fate pattern}

Initial comparative studies on vulva formation in clade $\mathrm{V}$ and clade IV species concentrated on patterning differences. Surprisingly, the vulval fate pattern of the equivalence group is relatively constant, and only three, basically "taxa-specific" patterns, for the Rhabditidae, Diplogastridae and Cephalobina, have been identified:

Rhabditidae pattern: $\mathrm{P}(4-8)$.p form a vulva equivalence group with the pattern $3^{\circ}-2^{\circ}-1^{\circ}-2^{\circ}-3^{\circ}$ (Sommer and Sternberg, 1994; Sommer and Sternberg, 1995). In this regard, C. elegans is itself an exception in that P3.p is a member of the equivalence group in 50\% of the individuals. Non-vulval cells in the anterior (P1.p to P3.p) and the posterior (P9.p to P11.p) body region fuse with the surrounding hypodermis (Figures 3, 5, 6A).

Diplogastridae pattern: In Pristionchus pacificus and all other species of the Diplogastridae studied to date, non-vulval cells in the anterior and posterior body region die by programmed cell death. These include $\mathrm{P}(1-4)$.p and $\mathrm{P}(9-11) . \mathrm{p}$ (see section 3.2.4. below). The vulva is formed by $\mathrm{P}(5-7) \cdot \mathrm{p}$ with a $2^{\circ}-1^{\circ}-2^{\circ}$ pattern (Figure 6A; Table 1 ; Sommer and Sternberg, 1996; Sommer, 1997).

Cephalobina pattern: In contrast to all species of the Rhabditidae and Diplogastridae, Cephalobina species form the vulva from the four precursor cells P(5-8).p (Sternberg and Horvitz, 1982; Sommer and Sternberg, 1996; Felix and Sternberg, 1997, Felix and Sternberg 1998; Felix et al, 2000). P(5,8).p have a $2^{\circ}$ fate and P(6,7).p have a mixed $1 \% 2^{\circ}$ fate with a UUTT and TTUU division pattern, respectively. The AC resides between P6.pp and P7.pa, whereas the AC resides above P6.p in species of the Rhabditidae and Diplogastridae. Interestingly, if a single VPC is isolated (that is, all other VPCs are ablated) the remaining cell will move beneath the AC and will have a TTTT pattern as is known from $C$. elegans. Thus, the wild type pattern UUTT and TTUU is a mixed $12^{\circ}$ fate. For 
simplicity, we consider the total pattern of the Cephabolina $2^{\circ}-1^{\circ}-1^{\circ}-2^{\circ}$ (Table 1). Cephalobina species differ in the fate of the non-vulval cells in the anterior and posterior body region. These cells fuse with the hypodermis in some species, but die by programmed cell death in others (Table 1; Sommer and Sternberg, 1996; Felix et al., 2000).
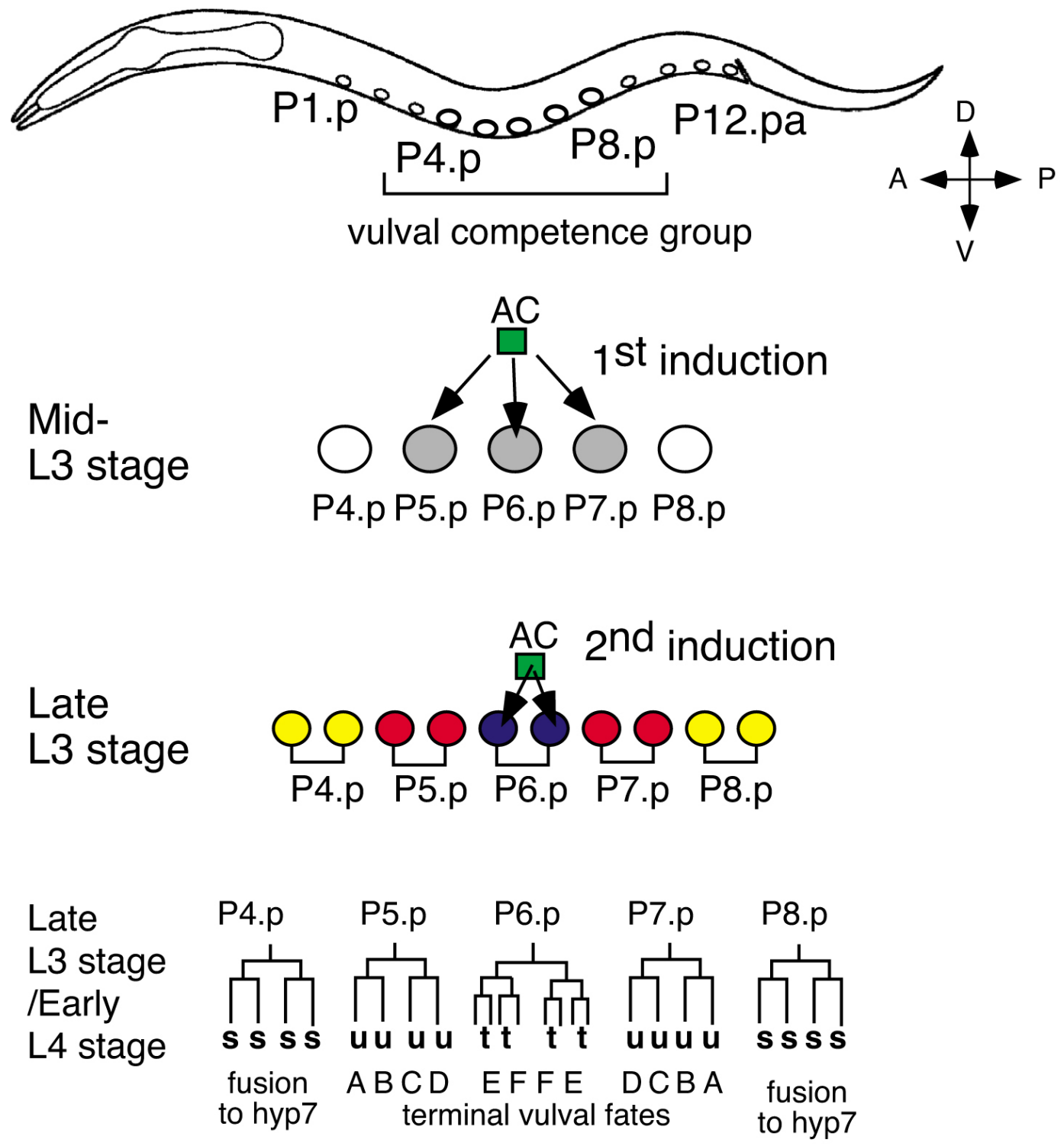

\section{Late L4 stage}

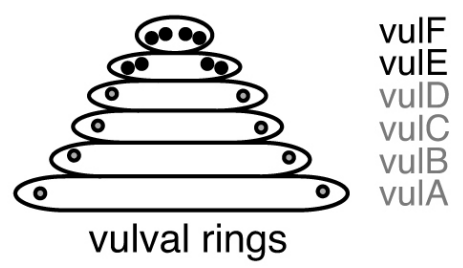

Figure 5. Model of vulva formation in $O$. tipulae. The vulva is formed by the progeny of $\mathrm{P}(5-7)$.p with a $2^{\circ}-1^{\circ}-2^{\circ}$ pattern as in $C$. elegans. $\mathrm{P} 4 . \mathrm{p}$ and $\mathrm{P} 8 . \mathrm{p}$ usually adopt a epidermal fate and their progeny fuse with the epidermal syncytium hyp7. P(4-8).p form a vulva equivalence group. The three vulval cell fates within the equivalence group are specified by two successive inductions by the AC on the Pn.p cells and their daughters (color code as in Fig. 4). The subsequent division pattern of each cell is given at the bottom. The sublineages of Pn.p granddaughters are abbreviated as follows: s, fuses with the hypodermal syncytium; $\mathrm{u}$, remained undivided; $\mathrm{t}$, divides transversally (left-right). After fusion of cells with the same terminal fate, the progeny of $\mathrm{P}(5-7)$.p give rise to six vulval rings, lettered vulA to vulF. Reprinted from Louvet-Vallee (2003). Copyright @ 2003 the Genetics Society of America. 
A

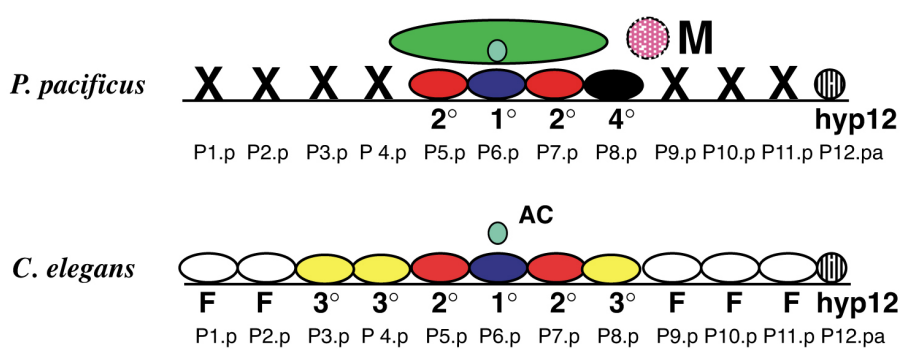

$\begin{array}{lcccccc} & \text { P3.p } & \text { P4.p } & \text { P5.p } & \text { P6.p } & \text { P7.p } & \text { P8.p } \\ \text { Wild-type } & X & X & 2^{\circ} & 1^{\circ} & 2^{\circ} & 4^{\circ} \\ \text { P(5-7).p ablated } & X & X & - & - & - & 4^{\circ} \\ \text { P(6,7).p ablated } & X & X & 2^{\circ} & - & - & 4^{\circ} \\ \text { P(6,7).p, M ablated } & X & X & 1^{\circ} & - & - & 4^{\circ} \\ \text { P(6-8).p } & X & X & 1^{\circ} & - & - & -\end{array}$

C

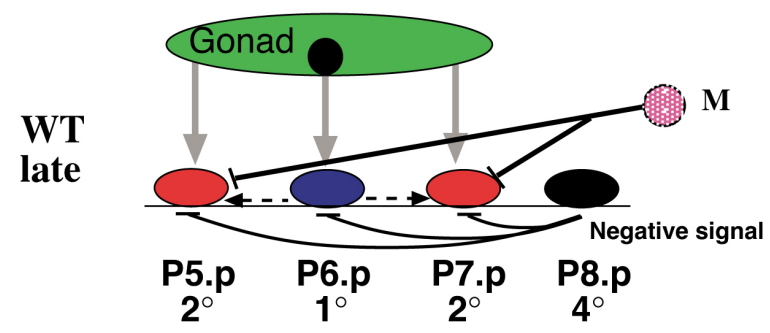

Figure 6. Schematic summary of the position and the fate of ventral epidermal cells in P. pacificus and comparison to $C$. elegans. (A) Vulval cell fate specification in P. pacificus. $\mathrm{P}(1-4,9-11)$.p die of programmed cell death (X). $\mathrm{P}(5-7)$.p form the vulva with a $2^{\circ}-1^{\circ}-2^{\circ}$ pattern. $\mathrm{P} 8$.p does not form part of the vulva and has a special fate designated as $4^{\circ}$ (black oval). The mesoblast $\mathrm{M}$ is born dorsolaterally to P8.p and acts, together with P8.p, to influence the cell fate of $\mathrm{P}(5,7)$.p. In $C$. elegans, $\mathrm{P}(1,2,9-11)$.p fuse with the hypodermis, whereas $\mathrm{P}(3-8)$.p form the vulva equivalence group. The VPCs adopt a $3^{\circ}$ (yellow), $2^{\circ}$ (red) or $1^{\circ}$ (blue) fate, respectively. (B) Summary of cell ablation experiments in P. pacificus. See text for details. (C) Model for cell-cell interactions during vulva development in P. pacificus. Vulva formation is induced by a continuous interaction by the somatic gonad. P8.p provides a lateral inhibition to $\mathrm{P}(5,7)$.p, mediated by the mesoblast $\mathrm{M}$ (black bars). Lateral inhibition influences the $1^{\circ}$ vs. $2^{\circ}$ cell fate decision of $\mathrm{P}(5,7)$.p. $\mathrm{P} 8$.p also provides a negative signal (black bars), which influences the vulva vs. non-vulval cell fate decision. Lateral signaling occurs between P6.p and P(5,7).p (dotted arrow). Reprinted from Sommer (2001), Copyright (2001) with permission from Elsevier.

\subsubsection{Modifications of vulva induction mechanisms}

Although the vulva cell lineage patterns differ between most species, the final vulva fate pattern is surprisingly conserved with the only major alteration being the $2^{\circ}-1^{\circ}-2^{\circ}$ pattern (clade V) vs. $2^{\circ}-1^{\circ}-1^{\circ}-2^{\circ}$ pattern (clade IV; Table 1). At the same time however, the exact cellular mechanisms of vulva induction vary greatly among species. Besides the absence of an inductive signal from the gonad in species with a posterior vulva, many of the didelphic species also differ strongly from C. elegans. Often, vulva induction occurs as a two-step process. In Oscheius tipulae and Rhabditella axei, the AC first provides a signal that specifies vulval fates. Later, after the first division of the VPCs, the AC provides a second, temporarily distinct signal that specifies the $1^{\circ}$ cell fate (Felix and Sternberg, 1997; Figures 4 and 5).

In clade IV nematodes, similar two-step inductions are common, but with variations in individual species. In Panagrolaimus sp. PS1732, the first signal comes from the gonad early in larval development, whereas the second signal is provided by the AC (Felix and Sternberg, 1997). In P. redivivus, both signals come from the gonad and in Halicephalobus sp. JB128 three signals are provided by the gonad and the AC, respectively (Felix et al., 2000; Figure 4). In the latter, an additional survival signal from the gonad is required to prevent the programmed cell death of the VPCs (Felix and Sternberg, 1998).

Taken together, these comparative studies reveal an enormous amount of evolutionary variability, mostly at the level of vulva induction. Although these cell ablation studies do not indicate which molecular signaling systems are at work in species with altered vulva induction, they provide important information for $C$. elegans itself. The phylogenetic interpretation in Figure 4 reveals that it is currently impossible to determine the induction mechanism of the last common ancestor from the nematodes compared so far. It is clear however, that the one-step mechanism 
seen in C. elegans is a highly derived character. Thus, the textbook example of AC signaling in C. elegans is not a common nematode pattern. Rather, it represents a derived feature that has most likely evolved relatively recently within the genus Caenorhabditis. At the same time, genetic analysis in $O$. tipulae and $P$. pacificus starts to provide insight into the evolution of molecular mechanisms of vulva induction (see below). In particular in P. pacificus, recent studies suggest that the molecular mechanisms of vulva induction changed during nematode evolution and that Wnt signaling has opposite functions in C. elegans and P. pacificus (Zheng et al., 2005).

\subsubsection{Oscheius}

O. tipulae is a hermaphroditic species, has a fast life cycle, is culturable on E. coli OP50 and can be frozen using standard protocols. Genetic analysis is straightforward and mutations can readily be discovered and maintained. Morpholino knockdown experiments have been introduced as a reverse genetic tool (Louvet-Vallee et al., 2003). Given that the Oscheius vulva is generated by a two-step mechanism (see above). Large-scale mutagenesis screens for vulva defective mutants have been performed to obtain insight into the mechanisms of vulva induction in this species (Dichtel et al., 2001; Louvet-Vallee et al., 2003; Dichtel-Danjoy and Felix, 2004; Figure 5). Surprisingly, most mutants in $O$. tipulae display phenotypes unknown from $C$. elegans. For example, the largest group of mutants affects the cell division pattern of the vulva precursor cells without changing their fate (Dichtel et al., 2001). Similar mutants have only rarely been observed in C. elegans (Kipreos et al., 1996; Fay and Han, 2000). This very interesting example shows that vulval cell cycle and fate can readily be genetically dissected in one species ( $O$. tipulae) but not the other $(C$. elegans) and that the outcome of genetic analyses is species-specific and depends on sometimes unpredictable circumstances.

A second group of $O$. tipulae vulva mutants affects the competence of the VPCs P(4-8).p. This group includes the lin-39 Hox gene, which seems to have a conserved role in the determination of the vulva equivalence group in nematodes (Louvet-Vallee et al., 2003). The third group of mutants specifically affects the vulva induction mechanism (Dichtel-Danjoy and Felix, 2004). These mutants show hypo - or hyperinduced vulval phenotypes. The hypoinduced iov-1 mutant reduces the level of both vulval induction steps indicating that both steps of induction share common molecular components (Dichtel-Danjoy and Felix, 2004). A MEK kinase inhibitor mimics the iov-1 mutation arguing that the RAS/MAPK pathway is involved in vulva induction in $O$. tipulae (Dichtel-Danjoy and Felix, 2004).

\subsubsection{Pristionchus}

P. pacificus has been established as a satellite organism in evolutionary developmental biology in the last ten years. Also $P$. pacificus propagates as self-fertilizing hermaphrodites, has a 4-day life cycle $\left(20^{\circ} \mathrm{C}\right)$ and can be cultured on OP50. P. pacificus is amenable to various cellular, genetic and molecular techniques successfully used in $C$. elegans. In addition to forward genetics, morpholino knockdown experiments provide a reverse genetic tool (Pires-daSilva and Sommer, 2004; Zheng et al., 2005).

In recent years, developmental and molecular studies have been complemented by a genomic approach. An integrated genome map of $P$. pacificus contains a genetic linkage map of approximately 400 molecular markers and a physical map of nearly 10.000 fingerprinted BAC clones (Srinivasan et al., 2002, Srinivasan et al.; 2003). A whole-genome sequencing project is ongoing (http://www.nhgri.nih.gov/12511858). A database, AppaDB, compiles the genomic information of $P$. pacificus in a comprehensive manner.

Vulva development in P. pacificus involves a set of evolutionary modifications when compared to C. elegans (Figure 6):

1. As typical for all members of the Diplogastridae, the non-vulval cells $\mathrm{P}(1-4,9-11) \cdot \mathrm{p}$, die by programmed cell death in P. pacificus (Sommer and Sternberg, 1996; Sommer, 1997).

2. Vulva induction is a continuous process that requires multiple cells of the somatic gonad and occurs over more than 10 hours of larval development (Sigrist and Sommer, 1999).

3. The epidermal cell P8.p and the mesoblast $M$ are involved in a novel interaction that prevents $\mathrm{P}(5,7) . \mathrm{p}$ from adopting the $1^{\circ}$ cell fate. This process has been designated as "lateral inhibition" in P. pacificus (Jungblut and Sommer, 2000). 
4. At least the posterior cell P8.p is involved in a negative signaling system that counteracts vulva induction by the somatic gonad. After ablation of $Z(1,4)$ at hatching, no vulva formation is seen. However, if $Z(1,4)$ and P8.p are ablated together, individual VPCs can adopt a vulval fate (Jungblut and Sommer, 2000).

P. pacificus vulva defective mutants have been isolated in large-scale mutagenesis screens (Eizinger, 1999) and the phenotype of mutations in the three homeotic genes Ppa-lin-39 (Eizinger and Sommer, 1997; Sommer et al., 1998; Grandien and Sommer, 2001), Ppa-mab-5 (Jungblut and Sommer, 1998; Jungblut et al, 2001) and Ppa-vab-7 (Jungblut and Sommer, 2000) have helped elucidating the molecular mechanisms of evolutionary change. Interestingly, Ppa-lin-39 is not required for vulva induction and thereby differs from Cel-lin-39 (Sommer et al., 1998). Ppa-mab-5 mutants show ectopic vulva differentiation, whereas Cel-mab-5 mutants form a normal vulva (Jungblut and Sommer, 1998). These results indicate that homologous homeotic genes changed their exact function during nematode evolution.

Recent studies in $P$. pacificus have shed first light on the molecular basis of vulva induction in nematodes other than C. elegans. Mutations in Ppa-lin-17/Frizzled and morpholino knockdowns of Ppa-lin-44/Wnt, Ppa-egl-20/Wnt, Ppa-mig-5/Dsh, Ppa-apr-1/APC and Ppa-bar-1/ß-cat result in gonad-independent vulva differentiation and a multivulva phenotype indicating a role of Wnt signaling in a negative signaling process (Zheng et al., 2005). In contrast in C. elegans, Wnt signaling has a positive role in vulva induction and mutations in Cel-bar-1/B-cat result in a hypoinduced phenotype (Eisenmann et al., 1998). Thus, the genetic control of vulva induction has diversified during evolution and differs strongly between P. pacificus and C. elegans.

\subsection{Male tail and body size evolution}

Besides vulva and gonad formation, early embryonic development and sex determination have been subject to detailed evolutionary analysis and they are covered in independent chapters (see The evolution of nematode sex determination and Embryological variation during nematode development). In addition, various other processes have been investigated. In males, the tail including the sensory rays, is of diverse morphology in rhabditid nematodes. Generally, male tail characters are used for species determination in the Rhabditidae (Sudhaus and Fitch, 2001), whereas the buccal cavity is the most variable structure in the Diplogastridae (Fürst v. Lieven and Sudhaus, 2000). Fitch and Emmons compared male tail development in 10 representative rhabditids and identified evolutionary changes in the position and order of homologous rays (Fitch and Emmons, 1995). These studies provided a basis for the evolutionary reconstruction of ray pattern evolution. Combining molecular phylogeny of the Rhabditidae with ray character information resulted in evolutionary hypotheses on specific character transformations (Fitch, 1997). Most interestingly, some of the evolutionary character state transformations resemble the phenotypic changes known from C. elegans mutations (Fitch, 1997).

Similar parallels between developmental genetic studies in C. elegans and evolutionary comparisons in related nematodes have been obtained by studying body size evolution (Flemming et al., 2000). Nematode species vary enormously in size and genetic and molecular studies have shown that a TGF- $\beta$ signaling pathway is a central growth control system in $C$. elegans (see TGF- $\beta$ signaling). Comparing more than 10 species of the genera Acrobeloides, Panagrellus, Rhabditoides, Pellioditis and Oscheius, a 10-fold body size variation was observed between these free-living species (Flemming et al., 2000). The two cellular mechanisms important in the evolution of body size are changes in the number of cells that fuse with the hypodermal syncytium and changes in the ploidy of hypodermal nuclei (Flemming et al., 2000). It should be noted, however, that even larger size variations are common in parasitic nematodes. The largest known species is Placentonema gigantissima, which is approximately 8 meters long and lives in the circulatory system of sperm whales.

\section{Conclusion}

Studying the evolution of developmental processes by looking at nematodes other than $C$. elegans has been a highly rewarding research topic. The selection of a few satellite organisms allows detailed genetic and molecular studies that, eventually, can move the evolutionary analysis to the mechanistic level. Such studies begin to reveal that it is the interplay of conservation and change of the function of developmental control genes and larger genetic networks that generates developmental novelty over evolutionary time.

\section{Acknowledgments}

I apologize to all those, the work of which I have been unable to review based on space restrictions. I thank A. Pires-daSilva, H. Zauner and M. Riebesell for critically reading the manuscript. 


\section{References}

Ambros, V., and Fixsen, W. (1987). Cell lineage variations among nematodes. In: Development as an Evolutionary Process. R.A. Raff and E.C. Raff, eds., Liss, New York. Abstract Article

Blaxter, M.L., de Ley, P., Garey, J.R., Liu, L.X., Scheldeman, P., Vierstraete, A., Vanfleteren, J.R., Mackey, L.Y., Dorris, M., Frisse, L.M., Vida, J.T., and Thomas, W.K. (1998). A molecular evolutionary framework for the phylum Nematoda. Nature 392, 71-75. Abstract Article

Ceol, C.J., and Horvitz, H.R. (2004). A new class of C.elegans synMuv genes implicates a Tip60/nuA4-like HAT complex as a negative regulator of Ras signaling. Dev. Cell 6, 563-576. Abstract Article

Delattre, M., and Félix, M.A. (2001A). Polymorphism and evolution of vulval precursor cell lineages within two nematode genera, Caenorhabditis and Oscheius. Curr. Bio. 11, 631-643. Abstract Article

Delattre, M., and Félix, M.A. (2001B). Development and evolution of a variable left-right asymmetry in nematodes: the handedness of P11/P12 migration. Dev. Bio. 232, 362-371. Article

Dichtel, M.L., Louvet-Vallée, S., Viney, M.E., Félix, M.A., and Sternberg, P.W. (2001). Control of vulval cell division number in the nematode Oscheius/Dolichorhabditis sp. CEW1. Genetics 167, 183-197. Abstract

Dichtel-Danjoy, M.L., and Félix, M.A. (2004). The two steps of vulval induction in Oscheius tipulae CEW1 recruit common regulators including a MEK kinase. Dev. Bio. 265, 113-126. Abstract Article

Eisenmann, D.M., Maloof, J.N., Simske, J.S., Kenyon C., and Kim S.K. (1998). The B-catenin homolog BAR-1 and LET-60 Ras coordinately regulate the Hox gene lin-39 during Caenorhabditis elegans vulval development. Development 125, 3667-3680. Abstract

Eizinger, A. (1999). Genetische Analyse der Vulvaentwicklung und genetische und molekulare Analyse des homöotischen Gens lin-39 im Nematoden Pristionchus pacificus. Dissertation Eberhard Karls Universität Tübingen.

Eizinger, A., and Sommer, R.J. (1997). The homeotic gene lin-39 and the evolution of nematode epidermal cell fates. Science 278, 353-540. Abstract Article

Fay, D.S., and Han, M. (2000). Mutations in cye-1, a Caenorhabditis elegans cyclin E homolog, reveal coordination between cell-cycle control and vulval development. Developement 127, 4049-4060. Abstract

Félix, M.A., and Sternberg, P.W. (1996). Symmetry breakage in the development of one-armed gonads in nematodes. Development 122, 2129-2142. Abstract

Félix, M.A., and Sternberg, P.W. (1997). Two nested gonadal inductions of the vulva in nematodes. Developemt 124, 253-259. Abstract

Félix, M.A., and Sternberg, P.W. (1998). A gonad-derived survival signal for vulval precursor cells in two nematode species. Curr. Bio. 8, 287-290. Abstract Article

Félix, M.A., de Ley, P., Sommer, R.J, Frisse, L.M., Nadler, S.A., Thomas, W.K., Vanfleteren, J.R., and Sternberg, P.W. (2000). Evolution of vulva development in the Cephalobina (nematoda). Dev. Bio. 221, 68-86. Abstract Article

Félix, M.A., Vierstraete, A., and Vanfleteren, J. (2001). Three biological species closely related to Rhabditis (Oscheius) pseudodolichura Körner in Osche, 1952. J. Nematol. 33(2-3), 104-109.

Flemming, A.J., Shen, Z.Z., Cunha, A., Emmons S.W., and Leroi A.M. (2000). Somatic polyploidization and cellular proliferation drive body size evolution in nematodes. PNAS 97(10), 5285-5290. Abstract Article

Fitch, D., and Emmons, S.W. (1995). Variable cell positions and cell contacts underlie morphological evolution of the rays in the male trails of nematodes related to Caenorhabditis elegans. Dev. Biol. 170, 564-582. Abstract Article 
Fitch, D.H. (1997). Evolution of male tail development in rhabditid nematodes related to Caenorhabditis elegans. Syst. Biol. 46, 145-179. Abstract

Fürst von Lieven,A., and Sudhaus, W. (2000). Comparative and functional morphology of the buccal cavity of Diplogastrina (Nematoda) and a first outline of the phylogeny of this taxon. J. Zool. Syst. Evol. Research 38, 37-63. Abstract Article

Grandien, K., and Sommer, R.J. (2001). Functional comparison of the nematode Hox gene lin-39 in C. elegans and $P$. pacificus reveals evolutionary conservation of protein function despite divergence of primary sequences. Genes Dev. 15, 2161-2172. Abstract Article

Jungblut, B., and Sommer, R.J. (1998). The P. pacificus mab-5 gene is involved in the regulation of ventral epidermal cell fates. Curr. Biol. 8, 775-778. Abstract Article

Jungblut, B., and Sommer, R.J. (2000). Novel cell-cell interactions during vulva development in Pristionchus pacificus. Development 127, 3295-3303. Abstract

Jungblut, B., Pires da Silva, A., and Sommer, R.J. (2001). Formation of the egg-laying system in Pristionchus pacificus requires complex interactions between gonadal, mesodermal and epidermal tissues and does not rely on single cell inductions. Development 128, 3395-3404. Abstract

Jungblut, B., and Sommer, R.J. (2000). The nematode even-skipped homolog vab-7 regulates gonad and vulva position in Pristionchus pacificus. Development 128, 253-261. Abstract

Kämpfe, L., and Wagner, H.J. (1964). Zucht und Verwendung von Nematoden als Versuchstiere. II. Rhabditis oxycerca de Man 1895. Zschr.Versuchstierk. 5, 46-58.

Kämpfe, L., and Schmidt, F.W. (1966). Zucht und Verwendung von Nematoden als Versuchstiere. III. Einzel- und Pärchenhaltung von Rhabditis oxycerca de Man 1895. Zschr.Versuchstierk. 8, 217-226.

Karp, X., and Greenwald, I. (2003). Post-transcriptional regulation of the E/daughterless ortholog HLH-2, negative feedback, and birth order bias during the AC/VU decision in C.elegans. Genes Dev. 17, 3100-3111. Abstract Article

Kimble, J., and Hirsh, D. (1979). The Postembryonic cell lineages of the hermaphrodite and male gonads in Caenorhabditis elegans. Dev. Biol. 70, 396-417. Article

Kimble, J. (1981). Alterations in cell lineage following laser ablation of cells in the somatic gonad of Caenorhabditis elegans. Dev. Biol. 87, 286-300. Abstract Article

Kipreos, E.T., Lander, I.E., Wing, J.P., He, W.W., and Hedgecock, E.M. (1996). Cul-1 is required for cell cycle exit in C. elegans and identifies a novel gene family. Cell 85, 829-839. Abstract Article

Louvet-Vallée, S., Kolutev, I., Podbilewicz, B., and Félix, M.A. (2003). Control of vulval competence and centering in the nematode Oscheius sp. 1 CEW1. Genetics 163,133-146. Abstract

Lu, X., and Horvitz, H.R. (1998). lin-35 and lin-53, two genes that antagonize a C. elegans Ras pathway, encode proteins similar to $\mathrm{Rb}$ and its binding protein RbAp48. Cell 95, 981-991. Abstract Article

Myers, T.R., and Greenwald, I. (2005). lin-35/Rb acts in the major hypodermis to oppose Ras-mediated vulval induction C. elegans. Dev. Cell 8, 117-123. Article

Newman, A.P., and Sternberg, P. (1996). Coordinated morphogenesis of epithelia during development of the Caenorhabditis elegans uterine-vulval connection. Proc. Nat. Acad. Sci. 93, 9329-9333. Abstract Article

Pires da Silva, A., and Sommer, R.J. (2004). Conservation of the global sex determination gene tra-1 in distantly related nematodes. Genes Dev. 18, 1198-1208. Abstract Article

Rudel, D., Riebesell, M., and Sommer. R.J. (2005). Gonadogenesis in Pristionchus pacificus and organ evolution: development, adult morphology and cell-cell interactions in the hermaphrodite gonad. Dev. Biol. 277, 200-221. Abstract Article 
Sherwood, D.R., and Sternberg, P. (2003). Anchor cell invasion into the vulva epithelium in C. elegans. Dev. Cell 5, 21-31. Abstract Article

Sigrist, C., and Sommer, R.J. (1999). Vulva formation in Pristionchus pacificus relies on continuous gonadal induction. Dev. Genes Evol. 209, 451-459. Abstract Article

Sommer, R.J., and Sternberg, P.W. (1994). Changes of induction and competence during the evolution of vulva development in nematodes. Science 265, 114-118. Abstract

Sommer, R.J., and Sternberg, P.W. (1995). Evoltuion of cell lineage and pattern formation in the vulval equivalence groups of rhabditid nematodes. Dev. Biol. 167, 61-74. Abstract Article

Sommer, R.J., and Sternberg, P.W. (1996). Apoptosis and change of competence limit the size of the vulva equivalence group in Pristionchus pacificus: a genetic analysis. Curr. Biol. 6(1), 52-59. Abstract Article

Sommer, R.J. (1997). Evolutionary changes of developmental mechanisms in the absence of cell lineage alterations during vulva formation in the Diplogastridae (nematoda). Developement 124, 243-251. Abstract

Sommer, R.J., Eizinger, A., Lee, K.Z., Jungblut, B., Bubeck, A., and Schlak, I. (1998). The Pristionchus HOX gene Ppa-lin-39 inhibits programmed cell death to specify the vulva equivalence group and is not required during vulval induction. Development 125, 3865-3873. Abstract

Sommer, R.J. (2000). Evolution of nematode development. Curr. Opin. Genet. Dev. 10, 443-448. Abstract Article

Sommer, R.J. (2001). As good as they get: cells in nematode vulva development and evolution. Curr. Opin. Cell Biol. 13, 715-720. Abstract Article

Srinivasan, J.,Sinz, W., Lanz, Chr., Brand, A., et al. (2002). A bacterial artificial chromosome-based genetic linkage map of the nematode Pristionchus pacificus. Genetics 162, 129-134. Abstract

Srinivasan, J., Sinz,W., Jesse, T., Wiggers-Perebolte,L., Jansen, K., Buntjer, J., van der Meulen, M., and Sommer, R.J. (2003). An integrated physical and genetic map of the nematode Pristionchus pacificus. Mol. Genet. Genomics 269, 715-722. Abstract Article

Srinivasan, J., Otto, G.W., Kahlow, U., Geisler, R., and Sommer, R.J. (2004). AppaDB: an AcedB database for the nematode satellite organism Pristionchus pacificus. Nucleic Acids Res. 32, D421-D422. Article

Sternberg, P.W., and Horwitz, H.R. (1981). Gonadal cell lineages of the nematode Panagrellus redivivus and implications for evolution by the modification of cell lineage. Dev. Bio. 88, 147-166. Abstract Article

Sternberg, P.W., and Horwitz, H.R. (1982). Postembryonic nongonadal cell lineages of the nematode Panagrellus redivivus: description and comparison with those of Caenorhabditis elegans. Dev. Biol. 93, 181-205. Abstract Article

Sudhaus, W., and Fitch, D .(2001). Comparative studies on the phylogeny and systematics of the Rhabditidae (Nematoda). J. Nematol. 33, 1-70. Abstract

Sudhaus, W., and Fürst von Lieven, A. (2003). A phylogenetic classification and catalogue of the Diplogastrina (Secernentea, Nematoda). J. Nem. Morph. Syst. 6, 43-90.

Sulston, J.E., and White, J.G. (1980). Regulation and cell autonomy during postembryonic development of Caenorhabditis elegans. Dev. Biol. 78, 577-597. Article

Zheng, M., Messerschmidt, D., Jungblut, B., and Sommer, R.J. (2005). Conservation and diversification of Wnt signaling function during the evolution of nematode vulva development. Nat. Genet. 37, 300-304. Abstract Article

All WormBook content, except where otherwise noted, is licensed under a Creative Commons Attribution License. 